\title{
Pola dan Motivasi Agroforestry Serta Kontribusinya Terhadap Pendapatan Petani Hutan Rakyat Di Kabupaten Polewali Mandar
}

\author{
Andi Irmayanti idris ${ }^{*}$, Andi Arafat ${ }^{1}$, Fatmawati $D^{2}$ \\ 1Program Studi Kehutanan, Universitas Sulawesi Barat, Majene \\ 2 Program Studi Agroekoteknologi, Universitas Sulawesi Barat, Majene \\ *Email : andi.irmayanti.idris@unsulbar.ac.id
}

\begin{abstract}
The purpose of this study is To identify agroforestry patterns and motivations and their contribution to the income of smallholder forest farmers. This research was carried out precisely in the Mirring Village of Binuang Subdistrict Polewali Mandar Regency in April to July 2019. The data accumulation used survey and interview methods.Data analysis uses descriptive qualitative and quantitative descriptive. The results showed that, farmers developed four forms of agroforestry-based community forest management systems, namely random mix form agroforestry, (Alternate Rows), Alternate Rows, agroforestry patterns at Atress Along Borders, and agroforestry patterns in the form of corridors (Alley Cropping). While community motivation in agroforestry planting patterns is influenced by perceived benefits, namely Economy with the highest percentage of $51.65 \%$, while in Social motivation (27.47\%). and lowest in Ecological motivation (20.88\%), the tendency of economic motivation affects farmers to choose cropping patterns. The agroforestry pattern that contributes the greatest income is the agroforestry A (Agrisilvikultur Atress Along Borders) pattern with an average income of Rp.14,873,222 with a percentage of $28.58 \%$. There are 3 types of agroforestry products which are the largest source of income namely Cocoa, Langsat and Durian.
\end{abstract}

Key words: Pattern, Motivation, Agroforestry, Private Forest

DOI: http://dx.doi.org/10.24259/jhm.v11i2.8177

\section{PENDAHULUAN}

Hutan merupakan salah satu sumberdaya alam yang mempunyai nilai eksternalitas lingkungan. Apabila pengelolaannya tidak dilakukan secara hati-hati maka akan menimbulkan kerusakan lingkungan. Usaha untuk mengelolah hutan dan mengembangkanya saat ini mendapat tantangan sejalan dengan tuntutan dunia internasional dan perubahan paradigma masyarakat.Salah satu tantangan tersebut adalah efesiensi pengelolaan hutan dan lahan dengan tetap memperhatikan kelestarian sumberdaya alam.Efisiensi pengelolaan hutan merupakan usaha pemanfaatan hutan agar secara ekonomis menguntungkan sementara kelestariannya tetap terjaga.Pemanfaatan lahan yang terbatas memberikan inovasi-inovasi pola yang secara bebas membentuk ruang pilihan kepada 
petani. Pola agroforestry merupakan jenis yang mempunyai prospek besar dan sangat menjanjikan petani untuk mencapai tujuan (Sabarnurdin dkk 2011).

Menurut P.K.R Nair (1987), agroforestry ialah sebagai sistem penggunaan lahan terpadu, yang memiliki aspek sosial, ekonomi, serta ekologi yang dilaksanakan melalui pengkombinasian pepohonan dengan tanaman pertanian dan ternak (hewan) baik itu secara bersama - sama atau bergiliran, sehingga dari satu unit lahan bisa tercapai hasil total nabati maupun hewan yang optimal dalam arti yang berkesinambungan.

Penduduk indonesia sebagian besar tinggal di daerah pedesaan yang lebih banyak menggantungkan hidupnya pada alam melalui usaha pertanian, atau perkebunan dan peternakan. Ketergantungan masyarakat pada hasil alam mendorong mereka untuk memanfaatkan lahanya secara optimal.Berangkat dari suatu sistem pengelolaan lahan yang orisinil di daerah - daerah yang semula lahannya tidak produktif, agroforestry merupakan salah satu alternatif solusi yang tepat dan baik untuk diterapkan. Agroforestry merupakan sistem pemanfaatan lahan yang meliputi penggabungan yang dapat diterima secara sosial dan ekologis antara pepohonan dengan tanaman pertanian dan/atau hewan-hewan, secara serempak atau berurutan, sehingga meningkatkan produktivitas tanaman dan hewan secara berkesinambungan dari unit lahan pertanian (Nair dalam Lahjie, 2001).

Pengelolaan hutan rakyat berbasis agroforestry tidak dapat dipisahkan dari kondisi masyarakat yang tentu memiliki motivasi tertentu seperti motivasi ekologi, ekonomi dan sosial. Faktor - faktor yang mempengaruhi motivasi ada dua yaitu faktor internal adalah faktor-faktor yang ada di dalam diri seseorang meliputi umur, tingkat pendapatan, pendidikan, dan pengalaman usahatani dan eksternal adalah faktor-faktor yang ada di luar aspek individu (Clegg, 2001 dalam Insani dkk 2015) meliputi kegiatan penyuluhan, tingkat kemudahan pemasaran dan akses informasi.

Pola agroforestry bisa saja menjadi alternatif yang lebih baik dan menguntungkan jika dibandingkan dengan kondisi yang ada. Dilihat dari aspek ekonomi, penerapan sistem agroforestry memiliki masa depan yang cerah, sebagai sebuah sistem yang memadukan berbagai jenis tanaman dalam satu lahan, maka akan memungkinkan naiknya produktifitas hasil panen. Logikanya setiap nilai tambahan memiliki nilai jual masing-masing, ketika dalam sistem agroforestry dikombinasikan dengan tanaman komersial maka total pendapatan pasca panen akan melimpah. Sebut saja dalam 
sistem agroforestry kita tanam kopi, coklat, rambutan, durian, jati, cengkeh dan merica. Maka jika jumlahnya melimpah uang yang akan didapat pun sangat banyak. Pertimbangan untung rugi ikut ambil bagian dalam keputusan kita. Begitu juga ketika lahan pertanian luas, pertimbangan ekonomi ikut mendominasi keputusan kita menggaji pesanggem (orang upahan) (Mahendra, 2009 dalam Panjaitan 2011).

Sistem agroforestry pada hutan rakyat di Desa Mirring Kecamatan Binuang Kabupaten Polewali mandar berkembang sudah sejak lama dan dilakukan secara turun temurun hingga saat ini.Hal ini dapat dilihat model - model hutan rakyat yang dikembangkan oleh masyarakat ditemukan adanya perpaduan antara tanaman pertanian dan tanaman kehutanan sehingga dapat dikategorikan sebagai sistem agroforestry (Daud dkk 2018). Secara administrasi Kecamatan Binuang berada di wilayah timur kota Polewali dengan luas $\pm 123,34 \mathrm{~km}$ yang mayoritas pendududknya berprofesi sebagai petani (Badan pusat Statistik 2017).

Beragamnya jenis tanaman yang dikembangkan oleh masyarakat melalui pertimbangan tertentu yang meliputi keadaan tempat tumbuh seperti sifat silviks disamping faktor tanah, iklim, budaya dan nilai ekonomi sehingga pemilihan jenis tanaman yang ditanam tidak sembarangan.Dengan kearifan lokal dibidang pertanian sebagai warisan turun temurun dari nenek moyangnya, masyarakat dapat mengenal dan memahami dalam memperlakukan lahan sesuai dengan kebutuhan dan kondisinya. Dengan demikian penelitian ini dilakukan untuk mengetahui Pola dan Motivasi Agroforestry serta kontribusinya terhadap pendapatan petani pada hutan rakyat di Desa Mirring Kecamatan Binuang Kabupaten Polewali Mandar. Tujuan penelitian ini adalah bagaimana pola dan motivasi serta seberapa besar kontribusi pendapatan petani dalam pengelolaan pola agroforestry.

\section{METODE PENELITIAN}

\subsection{Waktu dan Tempat}

Penelitian ini dilaksanakan pada bulan April sampai dengan bulan November tahun 2019 di Desa Mirring Kecamatan Binuang Kabupataen Polewali Mandar Provinsi Sulawesi barat. 


\subsection{Tahapan Pelaksanaan/Rancangan Penelitian}

Secara umum tahapan pelaksanaan penelitian ini terdiri atas beberapa langkah kegiatan meliputi :

a. Melakukan survei pendahuluan untuk mendapatkan informasi tentang masyarakat yang mengelolah lahan dengan pola agroforestry

b. Pengukuran dan pengamatan terhadap variabel identifikasiBentuk dan pola tanam agroforestry yang dikembangkan oleh masyarakat melalui

c. Pengukuran dan pengamatan terhadap variabel pengamatan langsung dan membuat plot pengamatan yang berukuran $(20 \times 20)$ meter.

d. Pengukuran dan pengamatan terhadap variabel identifikasi Motivasi yang mendorong masyarakat mengembangkan pola agroforestry melalui wawancara langsung

e. Pengukuran dan pengamatan terhadap variabel identifikasi kontribusi pendapatan petani melalui wawancara langsung secara struktur dan mendalam.

f. Mencatat semua hasil pengukuran dan pengamatan

g. Melakukan dokumentasi kegiatan pengukuran dan pengamatan

\subsection{Analisis Data}

\subsubsection{Analisis Pola-Pola dan Motivasi Agroforestry}

Analisis deskriptif kualitatif dilakukan untuk mengetahui pola-pola dan Motivasi agroforestry yang dikelolah oleh masyarakat. penentuan pola agroforestry didasarkan pada susunan ruang yang meliputi bentuk pagar (Atrees along borders) bentuk baris (Alternate rows) bentuk lorong (Alley cropping) dan bentuk campuran (Mixture random) Penentuan sampel di lapangan menggunakan plot dengan luasan $20 \mathrm{~m} \times 50 \mathrm{~m}$. Motivasi petani didasarkan pada manfaat agroforestry yang dirasakan langsung oleh masyarakat berupa manfaat (Ekonomi, Ekologi dan Sosial) yang diketahui melalui proses wawancara langsung.

\subsubsection{Nilai Ekonomi Produk Agroforestry}

Analisis kuantitatif digunakan untuk memperoleh gambaran mengenai kontribusi pendapatan yang meliputi sumber-sumber pendapatan dan pengeluaran responden baik dari hasil agroforestry dan di luar 
agroforestry. Selanjutnya dikelompokkan dan dilakukan perhitungan untuk kemudian disajikan dalam bentuk angka dan tabel sesuai dengan hasil yang diperoleh. Yang dirumuskan sebagai berikut :

a. Pendapatan Produk Agroforestry

$T R=P . Q$

Keterangan :

$\mathrm{TR}=$ Penerimaan total $(\mathrm{Rp})$

$P=$ Harga $(R p)$

$\mathrm{Q}=$ Jumlah Produksi $(\mathrm{Kg})$

b. Pendapatan Bersih

$\mathrm{I}=\mathrm{TR}-\mathrm{TC}$

Keterangan :

I = Pendapatan $(\mathrm{Rp})$

$\mathrm{TR}=$ Penerimaan Total $(\mathrm{Rp})$

$\mathrm{TC}=$ Biaya Total $(\mathrm{Rp})$

c. Menghitung pendapatan total, pendapatan dari dalam dan luar agroforestry

Keterangan :

Pendapatan total = jumlah rata-rata pendapatan per tahun

Pendapatan dari agroforestry $=$ jumlah nilai ekonomi dari seluruh jenis

Pendapatan luar agroforestry $=$ selisih antara pendapatan total dengan pendapatan dari agroforestry

d. Menghitung kontribusi

$\frac{\text { Pendapatan dari agroforestry }}{\text { pendapatan total }} \times 100 \%$

\section{HASIL DAN PEMBAHASAN}

\subsection{Penerapan Pola Agroforestri}

Karakteristik pola tanam agroforestry sangat tergantung pada pemilik lahan serta karakteristik lahanya. Tujuan akhir yang ingin dicapai yaitu prioritas produksi sehingga masyarakat membuat pola tanam yang berbeda antara lahan satu dengan lahan lainya. Di Desa Mirring Kecamatan Binuang Kabupaten Polewali Mandar Propinsi Sulawesi Barat dalam mengelolah lahan awalnya tidak mengenal sistem pola tanam agroforestry, mereka mengelolah lahan dengan cara yang sangat sederhana, dan mengikuti kebiasaan nenek moyang mereka yang terdahulu. Namun dengan melihat 
kegiatan dalam pengelolaan lahan yang mereka lakukan ada 4 (empat) pola tanam yang dilakukan oleh masyarakat yaitu

\section{a. Pola Agroforestry A (Agrisilvikultur Atress Along Borders)}

Pola agroforestri ini adalah pola agrisilvikultur pengaturan ruang bentuk pagar. Petani mengkombinasikan tanaman kehutanan seperti Jati Putih (Gmelina arborea), dengan tanaman pertaniaan seperti Cengkeh (Syzigium aromaticum), Coklat (Theobroma cacao), Kopi Arabica (Coffea arabica), Merica (Piper ningrum L), Cabai (Capsicum annum L).

Berdasarkan kombinasi tanaman yang diterapkan oleh petani maka hal ini sesuai dengan pendapat Lahjie (2001) yang menyatakan bahwa salah satu sistem agroforestri agrisilvikultur yaitu pemanfaatan lahan untuk produksi tanaman pertanian dan kehutanan secara bersama-sama. Adapun cara penanaman tanaman kehutanan menggunakan bentuk pagar yaitu komponen pohon disusun atau diatur pada bagian pinggir lahan dan tanaman pertanian berada dibagian tengah. Pohon-pohon yang ditanam mengelilingi lahan biasanya difungsikan sebagai pagar atau pembatas lahan di bawah pohon-pohon tepi yang ditanam dapat berperan sebagai tanda batas pemilikan lahan, pagar hidup, sekat bakar, tirai angin, dan dapat pula sebagai pelindung atau pengikat tanah jika ditanam pada tanah labil/tepi jurang. Hasil yang diperoleh dari pohon dapat berupa kayu bakar, kayu bangunan, pupuk hijau, pakan ternak buah dan lain-lain

b. Pola Agroforestry B (Agrisilvikultur Alternate Rows)

Pola agroforestry B adalah agrisilvikultur dengan pengaturan penanaman bentuk baris. Pola agroforestry ini menempatkan pohon dan tanaman pertanian secara berselang seling . pola ini dimungkinkan pada lahan yang relatif datar. Tanaman kehutanan ditanam dalam larikan yang diselang-seling dengan larikan tanam pangan, ruang-ruang terbuka diantara pohon-pohon relatif sempit. Bentuk pola tanam ini digunakan apabila tanaman pangan banyak memerlukan pupuk organik/pupuk hijau yang berasal dari guguran daun pohon (serasah). Pada sistem ini petani mengkombinasikan tanaman kehutanan seperti Meranti (Shorea Sp), Jati Putih (Gmelina arborea), Lamtoro( Leucania glauca)serta tanaman pertanian seperti Tomat (Lycopersicum esculentum), Kopi Arabika (Coffe arabica), Merica (Piper ningrum L) dan Cengkeh (Syzigium aromaticum), Langsat 
(Lansium domesticum), Durian (Durio Zibetinus), Rambutan (Nephelium lappaceum), Aren (Arenga pinnata), Pisang (Musa paradisiasa), Pala (Myristica fragrans), Kemiri (Aleurites mollucanus).

c. Pola Agroforestry C (Agrisilvikultur Alley Cropping)

Pola penanaman tanaman kehutanan ditanam menyerupai lorong. Pola kombinasi terdiri dari tanaman kehutanan dan pertanian. Kombinasi tanaman diantaranya Jati Putih (Gmelina arborea). Coklat (Theobroma cacao), Durian (Durio zibetinus), dan Langsat (Lansium domesticum). Pola tanaman kehutanan atau tanaman pertanian ditanam menyerupai bentuk jalur jalan. Adapun kegunaan pohon kehutanan atau tanaman pertanian yang digunakan untuk pengarah jalan dalam suatu lahan .

d. Pola Agroforestry D (Agrisilvikultur Mixture Random)

Pola Agroforestri D adalah pola agrisilvikultur pengaturan bentuk acak. Pada bentuk campuran acak, pohon-pohon hutan ditanam secara tidak beraturan (tidak mengikuti larikan atau jalur antara tanaman pangan). Bentuk ini sering ditemukan pada pertanian tradisional dimana pohon-pohon yang tumbuh berasal dari regenerasi alami (anakan atau trubusan) dan bukan berasal dari suatu penanaman. Dilihat dari sudut pengaturan ruang, pekarangan dapat pula digolongkan kedalam bentuk ini. Dimana pola kombinasi yang dikembangkan oleh masyarakat yaitu kombinasi tanaman kehutanan seperti Jati (Tectona grandis), Jati Putih (gmelina arborea) dan Bitti (Vitex copassus), dengan tanaman pertanian seperti Durian (Durio zibethinus), Aren (Arenga pinnata), Cengkeh (Syzigium aromaticum), Kopi Arabika (Coffea arabica), Coklat ( Theobroma cacao), Rambutan (Nephelium lappaceum), Langsat (Lansium domesticum), Cabai (Capsicum annuum), dan Jeruk (Cistrus Sp) .

Berdasarkan hasil pengamatan dan wawancara responden serta berdasarkan pola penanaman tersebut diatas maka masyarakat yang ada di Desa Mirring Kecamatan Binuang Kabupaten Polwali mandar telah menerapkan beberapa pola tanam agroforestry dalam bentuk ruang seperti digambarkan pada tabel dibawah ini : 
Tabel 1 . Tingkat Penerapan Pola Tanam agroforestry di Desa Mirring kecamatan Binuang

\begin{tabular}{|c|l|c|c|}
\hline \multirow{2}{*}{ No } & \multicolumn{1}{|c|}{ Pola Agroforestry } & \multicolumn{2}{|c|}{ Responden } \\
\cline { 3 - 4 } & & Frekwensi & Persentase \\
\hline 1 & Pagar ( Atress along borders) & 9 & 9,89 \\
\hline 2 & Baris ( Alternate rows) & 21 & 23,08 \\
\hline 3 & Lorong ( Alley cropping) & 7 & 7,69 \\
\hline 4 & Campuran (Mixture random) & 54 & 59,34 \\
\hline \multicolumn{2}{|c|}{ Jumlah } & 91 & 100 \\
\hline
\end{tabular}

Sumber : Data primer diolah (2019)

Tabel 1 diatas menunjukan bahwa dari 91 petani agroforestry yang menjadi responden di temukan 4 pola tanam berdasarkan bentuk ruang yakni 9,89\% responden menerapkan pola tanam Pagar (Atress along borders) 23,08\% responden menerapkan pola tanam Baris (Alternate rows), 7,69\% responden menerapkan pola tanam Lorong (Alley cropping), dan 59,34\% responden yang menerapkan pola tanam Campuran (mixture random).

Tingkat penerapan pola pengelolaan hutan rakyat berbasis agroforestry di Desa Mirring tertinggi sebesar 59,34\% terdapat pada pola tanam Campuran (Mixture random). Hal ini berarti lebih dari setengah jumlah petani mengelolah lahannya dengan pola tanam campuran. Berdasarkan hasil wawancara yang telah di lakukan, keadaan lahan dengan pola tanam campuran memang telah terbentuk sebelumnya karena merupakan lahan warisan sehingga mereka hanya melanjutkan pengelolaannya. Selain itu bentuk pengelolaan ini didasarkan pada kebiasaan atau kekompakan masyarakat dalam memilih bibit dengan pertimbangan tanaman yang mudah tumbuh dan memiliki nilai jual tinggi sehingga mereka dapat memperoleh keuntungan yang sebesar-besarnya untuk pemenuhan kebutuhan rumah tangga. Penerapan pola ini juga didasarkan pada kurangnya pemahaman masyarakat tentang persaingan unsur hara pada setiap jenis tanaman.

Pola tanam agroforestry bentuk baris (Selang-seling) merupakan pola tanam tertinggi yang kedua sebesar $23,08 \%$. penerapan pola tersebut dilakukan oleh petani dengan pemahaman bahwa melalui tanaman kehutanan yang ditanam akan memiliki nilai produksi kayu yang tinggi dan akan memberi keuntungan yang lebih karena akan dijual sebagai bahan bangunan dimasa yang akan datang. Meskipun petani belum memahami betul bahwa cara atau pola tanam yang mereka 
kembangkan atau lakukan adalah pola agroforestry, namun pemahaman dan tujuan mereka melakukan pola tanam tersebut adalah sebuah cara yang sangat mereka rasakan manfaatnya.

Pola tanam agroforestry bentuk pagar sebesar 9,89\% merupakan pola tanam dengan frekwensi responden 9 orang . Responden melakukanya karena sesuai hasil wawancara bahwa hal ini diterapkan dengan alasan lahan yang dimiliki sudah lama ditanami tanaman kehutanan dan setelah mereka melihat lahan tersebut sudah mengalami peningkatan kesuburan tanah maka tanah yang dibagian lembah, pohonnya ditebang untuk dimanfaatkan sebagai bahan bangunan dan sebagian sebagai kayu bakar, kemudian lahan yang sudah ditebang pohonya ditanami tanaman pertanian dan perkebunan sedangkan tanaman pohon yang masih tumbuh dibagian pinggir dijadikan pelindung tanaman pertanian. Sejalan dengan pendapat (Jumadil dkk. 2018) bahwa pentingnya hutan, yang menyediakan sumber daya hayati maupun non hayati sehingga dapat dimanfaatkan oleh manusia untuk menunjang kelangsungan hidupnya salah satu dengan pemanfaatan hasil hutan. Frekwensi terendah terdapat pada pola tanam agroforestry bentuk lorong (Jalur jalan) sebanyak 7 orang dengan persentase sebesar $7,69 \%$. Rendahnya nilai pada pola ini disebabkan karena lahan masyarakat yang berada tepat dijalur jalan hanya sedikit.

\subsection{Motivasi Petani Hutan Rakyat dalam Penerapan Pola Agroforestry}

Berdasarkan hasil wawancara dengan responden menunjukkan motivasi petani dalam berpola tanam agroforestry di Desa Mirring Kecamatan Binuang Kabupaten Polewali Mandar terlihat pada tabel berikut ini :

Tabel 2. Partisipasi Petani Hutan Rakyat Dalam Berpola Tanam Agroforestry

\begin{tabular}{|c|l|r|r|}
\hline No & \multicolumn{1}{|c|}{ Motivasi Agroforestry } & \multicolumn{2}{|c|}{ Responden } \\
\cline { 3 - 4 } & & \multicolumn{1}{|c|}{ Frekwensi } & \multicolumn{1}{|c|}{ Persentase } \\
\hline 1 & Ekonomi & 47 & 51,65 \\
\hline 2 & Ekologi & 19 & 20,88 \\
\hline 3 & Sosial & 25 & 27,47 \\
\hline \multicolumn{2}{|l|}{ Jumlah } & 91 & 100 \\
\hline
\end{tabular}

Sumber : Data Primer setelah diolah 2019 
Motivasi petani diketahui dari manfaat hutan rakyat yang diterima oleh petani. Menurut Taufik (2014) manfaat pengembangan hutan rakyat dapat dirasakan dalam jangka panjang, disamping itu banyak manfaat lain, terutama manfaat non material dari aspek pelestarian fungsi lingkungan yang tidak dirasakan secara langsung oleh petani. Sejalan dengan pendapat Djajapertjunda (2003) hutan rakyat memiliki manfaat secara ekologis yaitu sebagai sistem penyanggah kehidupan masyarakat dengan mengatur tata air, mencegah banjir, erosi dan sebagai prasarana untuk memelihara kualitas lingkungan hidup.

Agroforestry sangat diharapkan dapat membantu untuk mengoptimalkan hasil penggunaan lahan secara berkelanjutan untuk menjamin dan memperbaiki taraf hidup masyarakat. Pada daerah tropis beberapa faktor yakni secara ekonomi, ekologi, dan sosial adalah menjadi motivasi petani dalam menerapkan pola agroforestry (Vonn Maydell, 1986).

Tabel diatas menunjukkan bahwa 51,65\% manfaat ekonomi yang dirasakan oleh masyarakat merupakan persentase yang tertinggi. Hal ini dibuktikan dari hasil wawancara langsung responden yang di kombain dengan pendapatan rata-rata masyarakat dari luar dan dalam agroforestry. Masyarakat umumnya menyatakan bahwa penanaman pohon dan tanaman pertanian menguntungkan, karena jenis pohon kayu yang mereka tanam seperti Jati putih (Gmelina arborea) merupakan sumber utama bahan bangunan rumah mereka sendiri, sedangkan tanaman pertanian seperti pisang, jagung, kelapa, merica, tomat dan pala sebagai sumber makanan.

Tanaman pertanian lainya seperti Kopi, Cengkeh, Kakao, Durian, Langsat, dan Kemiri, akan mereka jual, dan ketika telah terjual hasilnya akan mereka gunakan untuk membiayai pendidikan anak -anak mereka dari SD sampai ke Perguruan Tinggi . hal inilah yang memotivasi petani untuk terus berusaha demi meningkatkan kesejahteraan hidup mereka. Sejalan dengan penelitian oleh Witantriasti (2010) mengatakan motivasi yang menjadi pendorong petani dalam berusaha tani hutan rakyat adalah manfaat dan keuntungan relatif yang diperoleh serta tujuan terhadap aktivitas usahatani menjadi tinggi, sedang dan rendah.

Partisipasi masyarakat Desa Mirring terhadap pengelolaan hutan rakyat dengan pola agroforestry yang dirasakan yakni hutan rakyat memberi dampak yang baik bagi kelestarian alam setempat, sehingga motivasi petani untuk mengelola hutan rakyat tetap terjaga. Menurut Witantriasti (2010) semakin baik partisipasi masyarakat berpola tanam agroforestry terhadap pembangunan 
hutan rakyat maka semakin baik juga pengelolaan hutan rakyat. Hal ini disebabkan oleh adanya kebutuhan hidup yang harus terpenuhi, dengan dibangunnya hutan rakyat pola agroforestry maka petani bisa menjual hasil produksi atau digunakan untuk konsumsi sendiri. Dengan sistem agroforestri, hasil yang didapat semakin banyak dan petani memiliki pendapatan dari hutan rakyat secara berkelanjutan.

$27,47 \%$ petani merasakan manfaat pola agroforestry secara sosial. Hasil persentase tersebut memiliki tingkat partisipasi sedang. Hal ini diketahui dari hasil wawancara responden yang menyatakan bahwa pengelolaan dengan pola tanam agroforestry selain merupakan pola tanam yang terbentuk secara alami dari warisan leluhur mereka juga merupakan bentuk pola tanam yang dilakukan berdasarkan kekompakan dan kebiasaan masyarakat setempat. Pemilihan bibit yang dilakukan bersama-sama Seperti Kakao, Kopi, Durian, Cengkeh, Aren dan Langsat. Karena nilai jual yang relatif stabil dan pemasaran yang tidak terlalu sulit menjadikan ketertarikan tersendiri oleh mereka .

Persentase pola agroforestry yang dirasakan masyarakat secara Ekologi sebesar 20,88\%. Partisipasi ini terbilang rendah, namun masyarakat tetap mengharapkan pola agroforestry ini dapat meningkatkan daya dukung ekologi manusia khususnya didaerah pedesaan. Dengan adanya sistem agroforestry diharapkan dapat memenuhi kaidah pengawetan tanah dan air agar tingkat kesuburan tanah dapat terjaga sehingga tercipta masyarakat yang mandiri dalam menata masa depan mereka.

\subsection{Kontribusi Pola Agroforestry Terhadap Pendapatan Petani}

Petani Desa Mirring memilih pola - pola agroforestry dan komposisi jenis tanaman didalamnya tidak lain diharapkan untuk memberikan kontribusi pendapatan kepada petani pengelolah lahan agroforestry. Kontribusi pendapatan diperoleh dari perhitungan antara pendapatan dari agroforestry dibagi dengan pendapatan total dikali seratus. Untuk mengetahui pola agroforestry yang memberikan kontribusi pendapatan terbesar dapat dilihat pada tabel dibawah ini : 
Tabel 3. Kontribusi Pola - pola Agroforestry Terhadap Pendapatan petani

\begin{tabular}{|c|l|c|c|c|c|}
\hline No & Pola Agroforestry & Responden & $\begin{array}{c}\text { Pendapatan } \\
\text { Bersih (Rp) }\end{array}$ & $\begin{array}{c}\text { Rata-rata } \\
\text { Pendapatan } \\
\text { (Rp) }\end{array}$ & $\begin{array}{c}\text { Kontribusi } \\
(\%)\end{array}$ \\
\hline 1 & $\begin{array}{l}\text { Pagar ( Atress along } \\
\text { borders) }\end{array}$ & 9 & 133.859 .000 & 14.873 .222 & 28,58 \\
\hline 2 & $\begin{array}{l}\text { Baris ( Alternate } \\
\text { rows) }\end{array}$ & 21 & 222.208 .000 & 10.581 .333 & 20 \\
\hline 3 & $\begin{array}{l}\text { Lorong (Alley } \\
\text { cropping) }\end{array}$ & 7 & 86.950 .000 & 12.421 .429 & 23,87 \\
\hline 4 & $\begin{array}{l}\text { Campuran (Mixture } \\
\text { random) }\end{array}$ & 54 & 764.492 .500 & 14.157 .269 & 27,21 \\
\hline \multicolumn{2}{|l|}{\begin{tabular}{l} 
Total (Rp) \\
\hline
\end{tabular}}
\end{tabular}

\section{Sumber : Data primer stelah diolah 2019}

Besar kecilnya nilai ekonomi jenis-jenis produk agroforestry sangat bergantung pada jumlah produk yang diambil, frekuensi pengambilan serta harga tiap satuanya. Responden pada lokasi penelitian hanya mengelolah dan menjual produk agroforestrynya saja mereka belum menjual kayu yang ada pada lahan agroforestry, berdasarkan hasil wawancara responden, petani hanya menjual kayu gergaji ataupun perbatang apabila ada yang ingin membangun rumah dan hanya ketika mereka membutuhkan uang barulah mereka menjual kayu mereka.

Berdasarkan data tabel diatas pola yang memeberikan kontribusi pendapatan terbesar adalah pola D Agroforestry dalam bentuk Pagar ( Atress along borders) dengan rata-rata pendapatan sebesar Rp 14.873.222 perkapita dengan kontribusi $28,58 \%$, pola yang memberikan kontribusi terbesar kedua adalah pada pola agroforestry dalam bentuk ruang Campuran (Mixture random) dengan pendapatan rata-rata perkapita sebesar $\operatorname{Rp} 14.157 .269$ dengan persentase $27,21 \%$, dan pola agroforestry yang mendapatankan kontribusi terkecil adalah pola agroforestry dalam bentuk 
ruang Lorong ( Alley cropping) dan Baris ( Alternate rows) yang masing -masing kontribusi pendapatanya sebesar Rp 12.421.429 dengan persentase 23,87 \% dan Rp 10.581 .333 dengan persentase $20 \%$.

Penerimaan terbesar petani dari komponen pertanian adalah pada tanaman Coklat yaitu sebesar Rp 527.249.000, penerimaan terbesar kedua adalah pada tamanan Langsat sebesar Rp 207.300.000 dan penerimaan terbesar ketiga adalah pada tanaman Durian sebesar Rp 181.212.500 . Menurut hasil wawancara yang dilakukan oleh tim surveyor, alasan petani memilih komposisi jenis yang beragam untuk lahan agroforestry mereka adalah sebagai berikut :

a. Keinginan untuk mendapatkan hasil yang bervariasi baik dari segi jenis maupun waktu pemanenanya

b. Pemanfaatan ruang lahan secara maksimal dengan jenis tanaman yang bernilai ekonomis tinggi dan tentunya sangat menguntungkan

\subsection{Perbandingan Pendapatan Dari Agroforestry dan Luar Agroforestry}

Masyarakat di Desa Mirring Kecamatan Binuang memiliki dua sumber pendapatan yaitu pendapatan dari pemanfaatan lahan agroforestry dengan pendapatan diluar agroforestry. Pendapatan dari agroforestry adalah pendapatan yang dihasilkan dari menjual produk agroforestry seperti kayu, buahbuahan serta tanaman palawija yang ada dalam kebun agroforestry sedangkan pendapatan petani dari luar agroforestry adalah pendapatan yang didapatkan dari kegiatan-kegiatan diluar dari bertani agroforestry seperti berprofesi sebagai tukang ojek, buruh, PNS, berladang, dan berdagang.

Hasil perhitungan menunjukkan bahwa pendapatan bersih dari pengelolaan agroforestry sebesar Rp. 1.207.509.500 dari 91 responden. Dengan membandingkan pendapatan masyarakat dari luar agroforestry dan pendapatan dalam pengelolaan agroforestry, maka dengan jelas dapat kita lihat pendapatan terbesar diperoleh dari pengelolaan agroforestry. Di mana selisih dari pendapatan diluar agroforestry sebesar $\mathrm{Rp}$ 403.770.000. rincian total pendapatan petani dari dan luar agroforestry dapat dilihat pada tabel dibawah ini: 
Tabel4. Total Pendapatan Masyarakat (RP/Tahun) Dari dan Luar Agroforestry

\begin{tabular}{|c|c|c|c|c|}
\hline \multirow[b]{2}{*}{ NO } & \multirow[b]{2}{*}{ NAMA } & \multicolumn{3}{|c|}{ PENDAPATAN PETANI } \\
\hline & & $\begin{array}{l}\text { PENDAPATAN LUAR } \\
\text { AGROFORESTRI (Rp) }\end{array}$ & $\begin{array}{c}\text { PENDAPATAN } \\
\text { AGROFORESTRI } \\
\text { (Rp) }\end{array}$ & $\begin{array}{c}\text { TOTAL } \\
\text { PENDAPATAN } \\
(\mathrm{Rp})\end{array}$ \\
\hline 1 & Responden 1 & 5.700 .000 & 4.325 .000 & 10.025 .000 \\
\hline 2 & Responden 2 & 0 & 39.880 .000 & 39.880 .000 \\
\hline 3 & Responden 3 & 5.300 .000 & 6.570 .000 & 11.870 .000 \\
\hline 4 & Responden 4 & 4.500 .000 & 2.445 .000 & 6.945 .000 \\
\hline 5 & Responden 5 & 9.900 .000 & 9.460 .000 & 19.360 .000 \\
\hline 6 & Responden 6 & 0 & 750 & 750 \\
\hline 7 & Responden 7 & 0 & 17.860 .000 & 17.860 .000 \\
\hline 8 & Responden 8 & 3.400 .000 & 2.500 .000 & 5.900 .000 \\
\hline 9 & Responden 9 & 8.000 .000 & 11.610 .000 & 19.610 .000 \\
\hline 10 & Responden 10 & 850 & 2.990 .000 & 3.840 .000 \\
\hline 11 & Responden 11 & 10.800 .000 & 7.166 .000 & 17.966 .000 \\
\hline 12 & Responden 12 & 0 & 60.652 .000 & 60.652 .000 \\
\hline 13 & Responden 13 & 3.600 .000 & 6.702 .000 & 10.302 .000 \\
\hline 14 & Responden 14 & 1.500 .000 & 9.439 .000 & 10.939 .000 \\
\hline
\end{tabular}


Jurnal Hutan dan Masyarakat. Vol. 11(2): 92-113, Desember 2019

Diserahkan : 2019-11-07 ; Diterima : 2019-12-24

ISSN: 1907-5316 ISSN ONLINE: 2613-9979

\begin{tabular}{|c|c|c|c|c|}
\hline 15 & Responden 15 & 3.600 .000 & 15.212 .000 & 18.812 .000 \\
\hline 16 & Responden 16 & 72.000 .000 & 6.713 .000 & 78.713 .000 \\
\hline 17 & Responden 17 & 9.000 .000 & 16.301 .000 & 25.301 .000 \\
\hline 18 & Responden 18 & 0 & 5.250 .000 & 5.250 .000 \\
\hline 19 & Responden 19 & 0 & 19.185 .000 & 19.185 .000 \\
\hline 20 & Responden 20 & 0 & 34.516 .000 & 34.516 .000 \\
\hline 21 & Responden 21 & 0 & 16.600 .000 & 16.600 .000 \\
\hline 22 & Responden 22 & 0 & 20.350 .000 & 20.350 .000 \\
\hline 23 & Responden 23 & 0 & 17.855 .000 & 17.855 .000 \\
\hline 24 & Responden 24 & 0 & 5.950 .000 & 5.950 .000 \\
\hline 25 & Responden 25 & 6.000 .000 & 7.349 .000 & 13.349 .000 \\
\hline 26 & Responden 26 & 0 & 36.050 .000 & 36.050 .000 \\
\hline 27 & Responden 27 & 0 & 750 & 750 \\
\hline 28 & Responden 28 & 2.700 .000 & 12.960 .000 & 15.660 .000 \\
\hline 29 & Responden 29 & 0 & 2.400 .000 & 2.400 .000 \\
\hline 30 & Responden 30 & 2.070 .000 & 16.145 .000 & 18.215 .000 \\
\hline 31 & Responden 31 & 9.900 .000 & 40.882 .000 & 50.782 .000 \\
\hline 32 & Responden 32 & 1.800 .000 & 2.220 .000 & 4.020 .000 \\
\hline 33 & Responden 33 & 0 & 9.490 .000 & 9.490 .000 \\
\hline
\end{tabular}


Jurnal Hutan dan Masyarakat. Vol. 11(2): 92-113, Desember 2019

Diserahkan : 2019-11-07 ; Diterima : 2019-12-24

ISSN: 1907-5316 ISSN ONLINE: 2613-9979

\begin{tabular}{|c|c|c|c|c|}
\hline 34 & Responden 34 & 9.000 .000 & 26.051 .000 & 35.051 .000 \\
\hline 35 & Responden 35 & 0 & 4.989 .000 & 4.989 .000 \\
\hline 36 & Responden 36 & 0 & 2.243 .000 & 2.243 .000 \\
\hline 37 & Responden 37 & 0 & 1.075 .000 & 1.075 .000 \\
\hline 38 & Responden 38 & 9.000 .000 & 10.570 .000 & 19.570 .000 \\
\hline 39 & Responden 39 & 18.000 .000 & 8.300 .000 & 26.300 .000 \\
\hline 40 & Responden 40 & 0 & 24.375 .000 & 24.375 .000 \\
\hline 41 & Responden 41 & 6.000 .000 & 750 & 6.750 .000 \\
\hline 42 & Responden 42 & 0 & 3.135 .000 & 3.135 .000 \\
\hline 43 & Responden 43 & 0 & 5.984 .000 & 5.984 .000 \\
\hline 44 & Responden 44 & 0 & 14.800 .000 & 14.800 .000 \\
\hline 45 & Responden 45 & 0 & 51.544 .000 & 51.544 .000 \\
\hline 46 & Responden 46 & 0 & 23.810 .000 & 23.810 .000 \\
\hline 47 & Responden 47 & 0 & 15.551 .000 & 15.551 .000 \\
\hline 48 & Responden 48 & 4.800 .000 & 4.465 .000 & 9.265 .000 \\
\hline 49 & Responden 49 & 5.000 .000 & 620 & 5.620 .000 \\
\hline 50 & Responden 50 & 0 & 3.454 .000 & 3.454 .000 \\
\hline 51 & Responden 51 & 0 & 7.570 .000 & 7.570 .000 \\
\hline
\end{tabular}


Jurnal Hutan dan Masyarakat. Vol. 11(2): 92-113, Desember 2019

Diserahkan : 2019-11-07 ; Diterima : 2019-12-24

ISSN: 1907-5316 ISSN ONLINE: 2613-9979

\begin{tabular}{|c|c|c|c|c|}
\hline 52 & Responden 52 & 0 & 3.942 .000 & 3.942 .000 \\
\hline 53 & Responden 53 & 12.000 .000 & 14.400 .000 & 26.400 .000 \\
\hline 54 & Responden 54 & 11.700 .000 & 545 & 12.245 .000 \\
\hline 55 & Responden 55 & 13.500 .000 & 5.324 .000 & 18.824 .000 \\
\hline 56 & Responden 56 & 0 & 30.822 .000 & 30.822 .000 \\
\hline 57 & Responden 57 & 36.150 .000 & 2.940 .000 & 39.090 .000 \\
\hline 58 & Responden 58 & 3.600 .000 & 500 & 4.100 .000 \\
\hline 59 & Responden 59 & 0 & 175 & 175 \\
\hline 60 & Responden 60 & 0 & 7.502 .000 & 7.502 .000 \\
\hline 61 & Responden 61 & 0 & 350 & 350 \\
\hline 62 & Responden 62 & 0 & 5.500 .000 & 5.500 .000 \\
\hline 63 & Responden 63 & 0 & 3.610 .000 & 3.610 .000 \\
\hline 64 & Responden 64 & 6.000 .000 & 2.180 .000 & 8.180 .000 \\
\hline 65 & Responden 65 & 0 & 11.930 .000 & 11.930 .000 \\
\hline 66 & Responden 66 & 1.000 .000 & 29.750 .000 & 30.750 .000 \\
\hline 67 & Responden 67 & 0 & 600 & 600 \\
\hline 68 & Responden 68 & 0 & 15.775 .000 & 15.775 .000 \\
\hline 69 & Responden 69 & 0 & 126.150 .000 & 126.150 .000 \\
\hline 70 & Responden 70 & 7.500 .000 & 17.525 .000 & 25.025 .000 \\
\hline
\end{tabular}


Jurnal Hutan dan Masyarakat. Vol. 11(2): 92-113, Desember 2019

Diserahkan : 2019-11-07 ; Diterima : 2019-12-24

ISSN: 1907-5316 ISSN ONLINE: 2613-9979

\begin{tabular}{|c|c|c|c|c|}
\hline 71 & Responden 71 & 4.500 .000 & 8.330 .000 & 12.830 .000 \\
\hline 72 & Responden 72 & 0 & 3.900 .000 & 3.900 .000 \\
\hline 73 & Responden 73 & 8.100 .000 & 26.255 .000 & 34.355 .000 \\
\hline 74 & Responden 74 & 0 & 15.750 .000 & 15.750 .000 \\
\hline 75 & Responden 75 & 36.000 .000 & 1.112 .500 & 37.112 .500 \\
\hline 76 & Responden 76 & 0 & 23.350 .000 & 23.350 .000 \\
\hline 77 & Responden 77 & 0 & 56.300 .000 & 56.300 .000 \\
\hline 78 & Responden 78 & 0 & 2.975 .000 & 2.975 .000 \\
\hline 79 & Responden 79 & 1.700 .000 & 5.800 .000 & 7.500 .000 \\
\hline 80 & Responden 80 & 8.000 .000 & 2.980 .000 & 10.980 .000 \\
\hline 81 & Responden 81 & 0 & 300 & 300 \\
\hline 82 & Responden 82 & 18.000 .000 & 1.950 .000 & 19.950 .000 \\
\hline 83 & Responden 83 & 0 & 13.485 .000 & 13.485 .000 \\
\hline 84 & Responden 84 & 0 & 1.364 .000 & 1.364 .000 \\
\hline 85 & Responden 85 & 18.000 .000 & 7.400 .000 & 25.400 .000 \\
\hline 86 & Responden 86 & 0 & 13.005 .000 & 13.005 .000 \\
\hline 87 & Responden 87 & 5.600 .000 & 4.590 .000 & 10.190 .000 \\
\hline 88 & Responden 88 & 0 & 10.150 .000 & 10.150 .000 \\
\hline 89 & Responden 89 & 0 & 11.800 .000 & 11.800 .000 \\
\hline
\end{tabular}




\begin{tabular}{|c|l|r|r|r|}
\hline 90 & Responden 90 & 0 & 8.100 .000 & 8.100 .000 \\
\hline 91 & Responden 91 & 0 & 31.280 .000 & 31.280 .000 \\
\cline { 2 - 5 } & \multirow{2}{*}{ Total (Rp) } & 403.770 .000 & 1.207 .509 .500 & 1.611 .279 .500 \\
\hline
\end{tabular}

Sumber : Data primer setelah diolah, 2019

Keseluruhan pendapatan petani pengelolah agroforestry di Desa Mirring Kecamatan Binuang berasal dari kawasan hutan rakyat dan di luar kawasan hutan rakyat. Dari hasil penelitian diketahui bahwa pendapatan dari hutan dapat berupa produk-produk agroforestry yang mereka kembangkan di lahan mereka, sementara pendapatan dari luar hutan berupa kegiatan lain diluar kawasan hutan seperti berdagang, nelayan, buruh dan honorer. Hal ini didukung oleh penelitian Senoaji (2009) yang menyatakan bahwa pendapatan masyarakat dapat dibedakan menjadi pendapatan yang diperoleh dari kegiatan di dalam kawasan hutan dan pendapatan lainya di luar kawasan hutan. Pendapatan dari kawasan hutan adalah pendapatan yang diperoleh dari masyarakat akibat kegiatanya yang dilakukan di kawasan hutan.

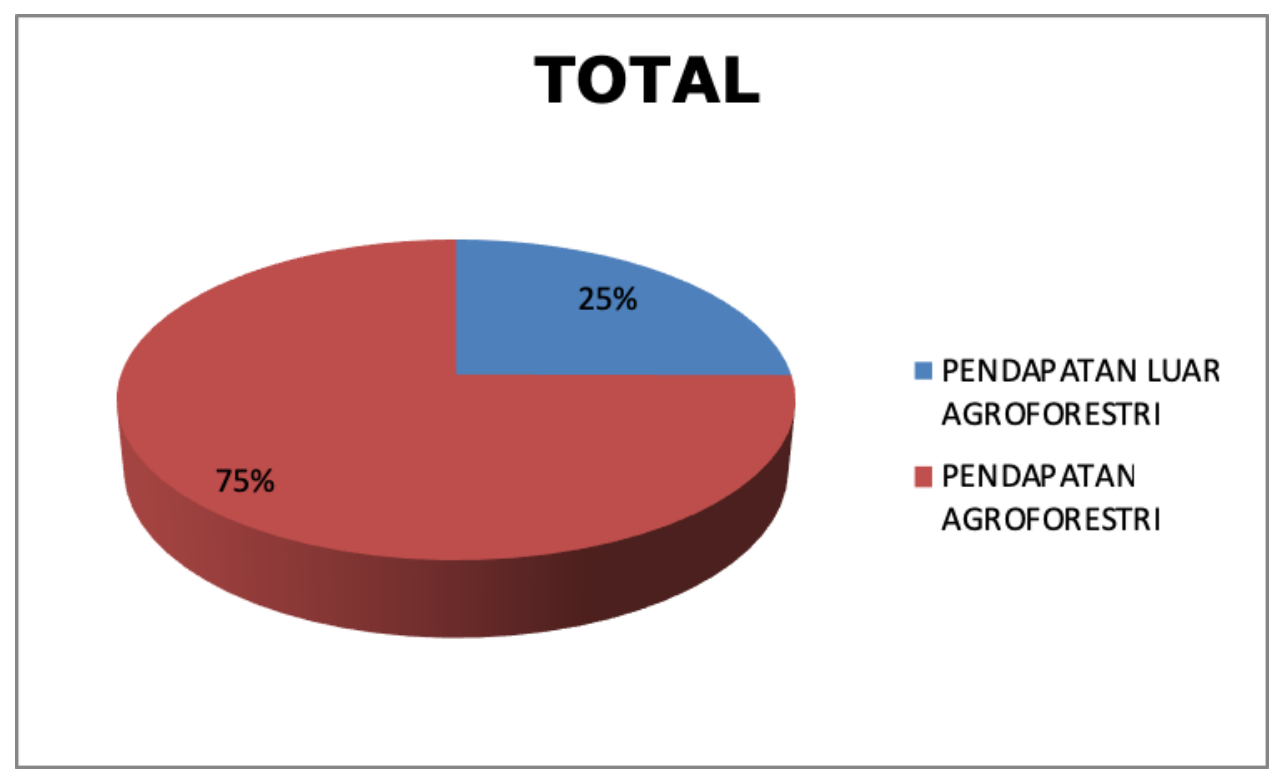

Gambar 1. Perbandingan Pendapatan Agroforestry dan Luar Agroforestry 
Total pendapatan masyarakat dari praktik agroforestry dan luar agroforestry dalam satu tahun dapat mencapai Rp1.611.279.500 seperti pada tabel 4. Hasil perhitungan menunjukkan bahwa pendapatan masyarakat dari pemanfaatan produk agroforestry sebesar Rp 1.207.509.500 . Atau sekitar $63,77 \%$ Sementara pendapatan masyarakat dari luar pemanfaatan produk agroforestry hanya sebesar Rp 403.770 .000 atau sekitar 25,08\%. dari lampiran tersebut dapat diketahui bahwa pendapatan masyarakat dari produk-produk agroforestry hanya memberi kontribusi sebesar 38,69 \% saja. Kondisi ini mengindikasikan bahwa petani hutan rakyat di Desa Mirring belum mengelolah dan memanfaatkan lahan agroforestry mereka secara maksimal.

\section{KESIMPULAN}

Berdasarkan hasil penelitian yang merujuk pada tujuan penelitian ini, maka disimpulkan bahwa Masyarakat petani di Desa Mirring, Kecamatan Binuang, Kabupaten Polewali Mandar mengembangkan empat bentuk sistem pengelolaan hutan rakyat berbasis agroforestry dan memiliki frekuensi responden dan tingkat persentase yang berbeda. Persentase tertinggi sebesar 59,43\% dengan frekuensi sebanyak 54 responden yaitu pada pola agroforestry bentuk campuran acak, (Mixture Random), diikuti oleh pola agroforestry bentuk baris (Alternate Rows) sebesar 23,08\% dengan frekwensi responden sebanyak 21 . dan nilai terendah oleh pola agroforestry bentuk Pagar (Atress Along Borders) dan pola agroforestry bentuk lorong (Alley Cropping) masing-masing sebesar 9,89\% dan frekwensi responden 9 , dan 7,69\% dengan frekwensi sebanyak 7 responden. Sedangkan Motivasi masyarakat dalam berpola tanam agroforestry dipengaruhi oleh manfaat yang dirasakan yaitu Ekonomi dengan persentase tertinggi sebesar $51,65 \%$, sedang pada motivasi Sosial(27,47\%).dan terendah pada motivasi Ekologi (20,88\%), Kecendrungan motivasi ekonomi mempengaruhi Petani memilih pola tanam dan Pola agroforestry yang memberikan kontribusi pendapatan terbesar adalah pola agroforestry A (Agrisilvikultur Atress Along Borders) dengan pendapatan rata-rata Rp. 14.873 .222 dengan persentase 28,58\%, terbesar kedua adalah pola agroforestry D, (Agrisilvikultur Mixture Random) dengan pendapatan rata-rata Rp. 14.157.269 dengan persentase $27,21 \%$, dan kontribusi terkecil masing-masing pola agroforestry C (Agrisilvikultur Alley Cropping) Rp 12.421 .429 persentase 23,87\%, pola agroforestry B (Agrisilvikultur Alternate Rows) rata-rata pendapatanya sebesar Rp 10.581 .333 dengan persentase $20 \%$. Terdapat 3 jenis 
produk agroforestry yang merupakan sumber pendapatan terbesar yakni Kakao, Langsat dan Durian.

\section{DAFTAR PUSTAKA}

Badan Pusat Statistik. 2017. Statistik Kecamatan Binuang. Polewali Mandar (ID): Pemerintah Kabupaten Polewali Mandar.

Daud I, Arafat A, Rahmania. 2018. Nilai Ekonomi Langsung Berbagai Sistem Pengelolaan Hutan Rakyat di Desa Mirring Kabupaten Polman Sulawesi Barat. Jurnal Hutan dan Masyarakat 10 (1), 185-191.

Djajapertjunda S. 2003. Mengembangkan Hutan Milik di Jawa. Buku. Bandung. Alqaprint Jatinangor. $88 \mathrm{HIm}$.

Insani F N, Asihing K, Rudi H. 2015. Motivasi Petani dalam Mengelolah Hutan Rakyat di Desa Sukoharjo 1 Kecamatan Sukoharjo Kabupaten Pringsewu. Jurnal Sylva Lestari 3(3), 51-62.

Jumadil, Imran R dan Abdul H. 2018. "Analisis Penggunaan Kayu Bakar Masyarakat Di Dusun Salena Kelurahan Buluri Kecamatan Ulujadi Kota Palu":dalam Jurnal Warta Rimba Volume 6 (hlm.21-27).Palu : Univeristas Tadulako.

Lahjie. A. M. 2001. Tehnik Agroforestry. Grafika UPNV. Jakarta.

Mahendra, F. 2009. Sistem Agroforestri dan Aplikasinya. Graha IImu. Yogyakarta.

P. K. R Nair. 1987. Agroforestry System Inventory. Agroforestry System S : 301 - 317. Marinus Nyhoff The Netherlands.

Sabarnurdin S, Budiadi, Suryanto P. 2011. Agroforestri Untuk Indonesia: Strategi Kelestarian Hutan dan Kemakmuran. Yogyakarta: Terangkata Media. 
瓷

Jurnal Hutan dan Masyarakat. Vol. 11(2): 92-113, Desember 2019

Diserahkan : 2019-11-07 ; Diterima : 2019-12-24

ISSN: 1907-5316 ISSN ONLINE: 2613-9979

Vonn Maydell H.J. 1986. Agroforest Twitschat in den Tropen und Subtropen. In Rehm, S. (Ed). 1986. Grundlagen des Pflanzenabbaus in den Tropen und Subtropen. Eugenulmer. Stuttgart.

Witatriasti, Tantri. 2010. Faktor-Faktor yang Mempengaruhi Intensitas Pengelolaan Hutan Rakyat di Desa Gunung Sari Kecamatan Pamijaan Kabupaten Bogor. Dalam Jurnal Penelitian Jurnal Sylva Lestari 3(3), 51-62. 